\title{
Capsulodesis. Cirugía Liberata La historia de su nacimiento. Relato entre un abuelo y su nieto en una tarde distendida
}

\author{
Prof. Eduardo A. Zancolli, Eduardo P. Zancolli* \\ "Sector de Miembro Superior, Fundación Favaloro, Ciudad Autónoma de Buenos Aires, Argentina
}

En 1956, un cirujano plástico de Puerto Alegre (Brasil) viajaba a Buenos Aires. Presentaba como antecedente una lesión de los nervios mediano y cubital, con el desarrollo de una deformidad en garra (flexible) de los cuatro dedos. El doctor se encontraba en viaje hacia Europa donde realizaría una consulta en Inglaterra. Durante su escala en Buenos Aires, el doctor brasileño visitó el antiguo Sanatorio Finochietto, donde por recomendación del Dr. Héctor Marino, presenció una cirugía del Dr. Eduardo A. Zancolli.

Fue, después de aquel evento, que el doctor de Puerto Alegre decidió interrumpir su viaje a Europa para operarse en Buenos Aires con Zancolli.

El Dr. Zancolli, en aquel momento, utilizaba el procedimiento de Stiles-Bunnell para la corrección de la garra cubital. ${ }^{1}$ Esta, utilizada en aquel paciente, consta de retraer en la palma el tendón superficial del dedo medio luego de su sección a nivel digital y dividirlo en cuatro lengüetas. Cada lengüeta del tendón se pasa por el canal lumbrical palmar al ligamento intermetacarpiano, para insertarse finalmente en la banda lateral digital.

Al retornar esa tarde a su casa, el Dr. Zancolli cuenta que se sentó en un sillón a revisar lo realizado en la cirugía. Se cuestionaba el haber estado horas con el paso de tendones para reconstruir la garra. Era un procedimiento complejo. Basado en un principio personal de que "ante diferentes procedimientos quirúrgicos con igual resultado, el más sencillo es el mejor”, el Dr. Zancolli reflexionó en busca de alguna manera más sencilla de corregir la garra digital. Cuenta que, en esa búsqueda, recordó algo que había leído previamente en el libro de Emmanuel Kaplan. ${ }^{2}$ "Cuando de manera congénita se presenta contractura en flexión metacarpofalángica ante una parálisis cubital, la garra no se desarrolla y el tendón extensor puede extender las articulaciones interfalángicas”.

A partir de ese recuerdo, el Dr. Zancolli interpreta que habría que reproducir quirúrgicamente aquello que congénitamente ocurría para que la garra no se desarrolle, es decir, una capsuloplastia volar metacarpofalángica, para evitar así la hiperextensión articular y permitir que el aparato extensor extrínseco extienda los dedos.

Durante su carrera de Medicina en Buenos Aires, el Dr. Zancolli vivía en una pensión para estudiantes donde Liberata, la cocinera de dicha pensión, presentaba una parálisis cubital con garra digital. El Dr. Zancolli, al día siguiente de la cirugía al médico de Puerto Alegre, fue a dicha pensión y encontró a Liberata limpiando los platos de los estudiantes luego del almuerzo. El doctor la examinó y vio que Liberata era candidata para la cirugía de capsulodesis volar y así mejorar la biomecánica digital. La convenció, con gran esfuerzo, de que se operara. Esa tarde, en el Hospital del Quemado de Buenos Aires, donde el Dr. Zancolli operaba habitualmente, se realizó en aquella cocinera la primera capsulodesis volar para garra cubital. De allí proviene que el Dr. Zancolli denominara a dicho procedimiento Cirugía Liberata.

En octubre de 1957, el Dr. Zancolli publica, en el Journal of Bone and Joint Surgery, la descripción de la capsulodesis volar. ${ }^{3}$

Las lesiones del nervio cubital, o de ambos nervios mediano y cubital, resultan en la deformidad en garra digital. Esta condición se presenta con hiperextensión metacarpofalángica y flexión interfalángica por la pérdida de función de los músculos intrínsecos que normalmente flexionan la articulación metacarpofalángica y extienden las interfalángicas.

\footnotetext{
Recibido el 30-7-2020. Aceptado luego de la evaluación el 31-7-2020 • Prof. EDUARDO A. ZANCOLLI • pablozancolli@yahoo.com.ar Cómo citar este artículo: Zancolli EA, Zancolli EP. Capsulodesis. Cirugía Liberata. La historia de su nacimiento. Relato entre un abuelo y su nieto en una tarde distendida. Rev Asoc Argent Ortop Traumatol 2020;85(Supl.):S45-S47. https://doi.org/10.15417/issn.1852-7434.2020.85.4S.1177
} 
Para la corrección de la garra flexible es necesario limitar la hiperextensión de las articulaciones metacarpofalángicas involucradas en la deformidad para restablecer la biomecánica extensora extrínseca. La literatura describe diferentes procedimientos para la corrección de la garra cubital, estos pueden categorizarse en estáticos y dinámicos. ${ }^{4-6}$ Si la prueba de Bouvier es positiva, los procedimientos estáticos, como la capsulodesis volar, tienen su indicación. $^{7}$

La capsulodesis descrita por Zancolli se realiza a través de una incisión de manera longitudinal palmar a nivel metacarpofalángico (Figura 1). Se identifican y se separan los paquetes neurovasculares. Luego se realiza la apertura de la polea A1 y los tendones flexores se separan identificándose así la cápsula volar metacarpofalángica (Figura 2A). Se realiza una capsuloplastia en la que se talla un colgajo capsular de base distal (Figura 2B). Este colgajo se avanza de manera proximal y se ancla al hueso para obtener un acortamiento capsular limitando la extensión articular, obteniendo una posición en $20^{\circ}$ de flexión metacarpofalángica. En el posoperatorio, los dedos se inmovilizan en flexión metacarpofalángica por 30 días, dejando las articulaciones interfalángicas libres. Las articulaciones interfalángicas deben movilizarse de manera activa y pasiva a partir de la segunda semana posoperatoria para evitar adherencias de los tendones flexores. Luego de retirar el yeso, se comienza con la rehabilitación.

En este breve relato, se comparte el nacimiento de una técnica: la Cirugía Liberata. Técnica que fue fruto del conocimiento de la anatomía y la biomecánica de la mano, además de la búsqueda constante por aquello que sea eficaz y sencillo.

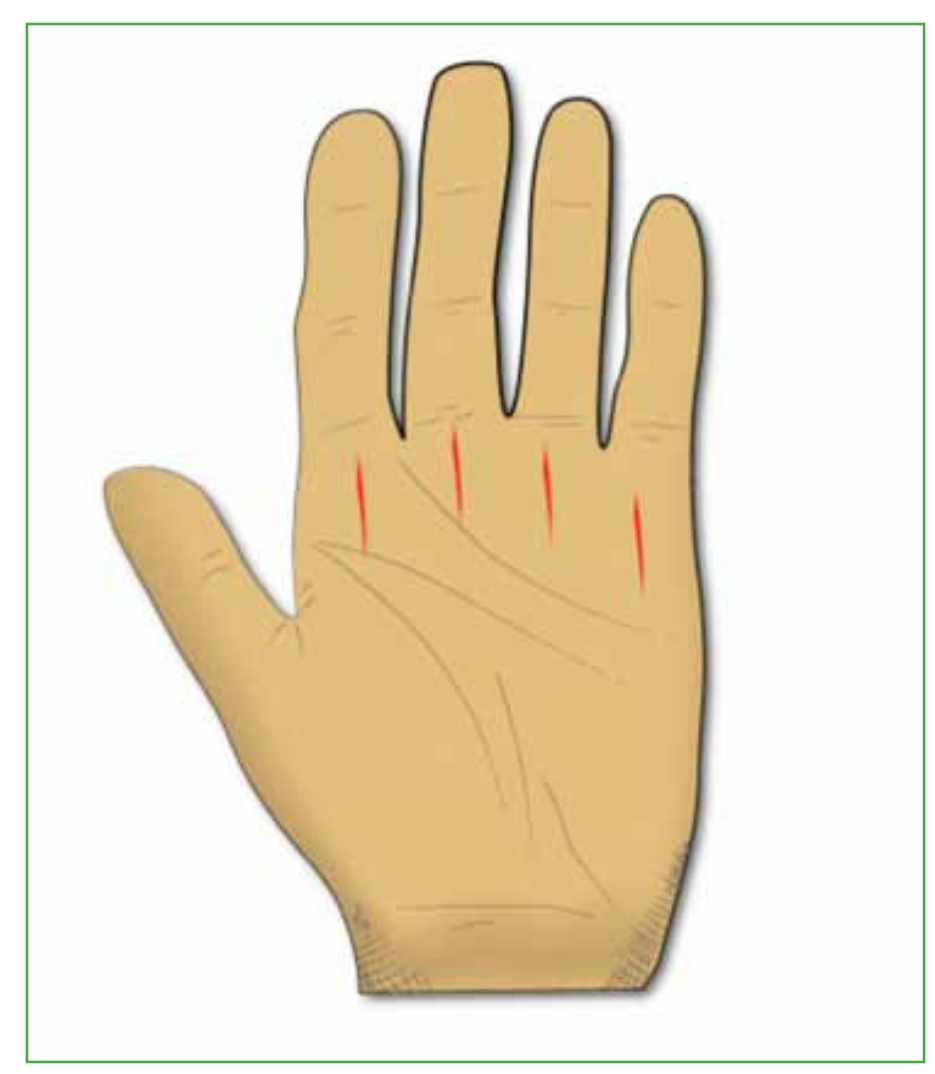

Figura 1. Incisión longitudinal palmar a nivel metacarpofalángico. 


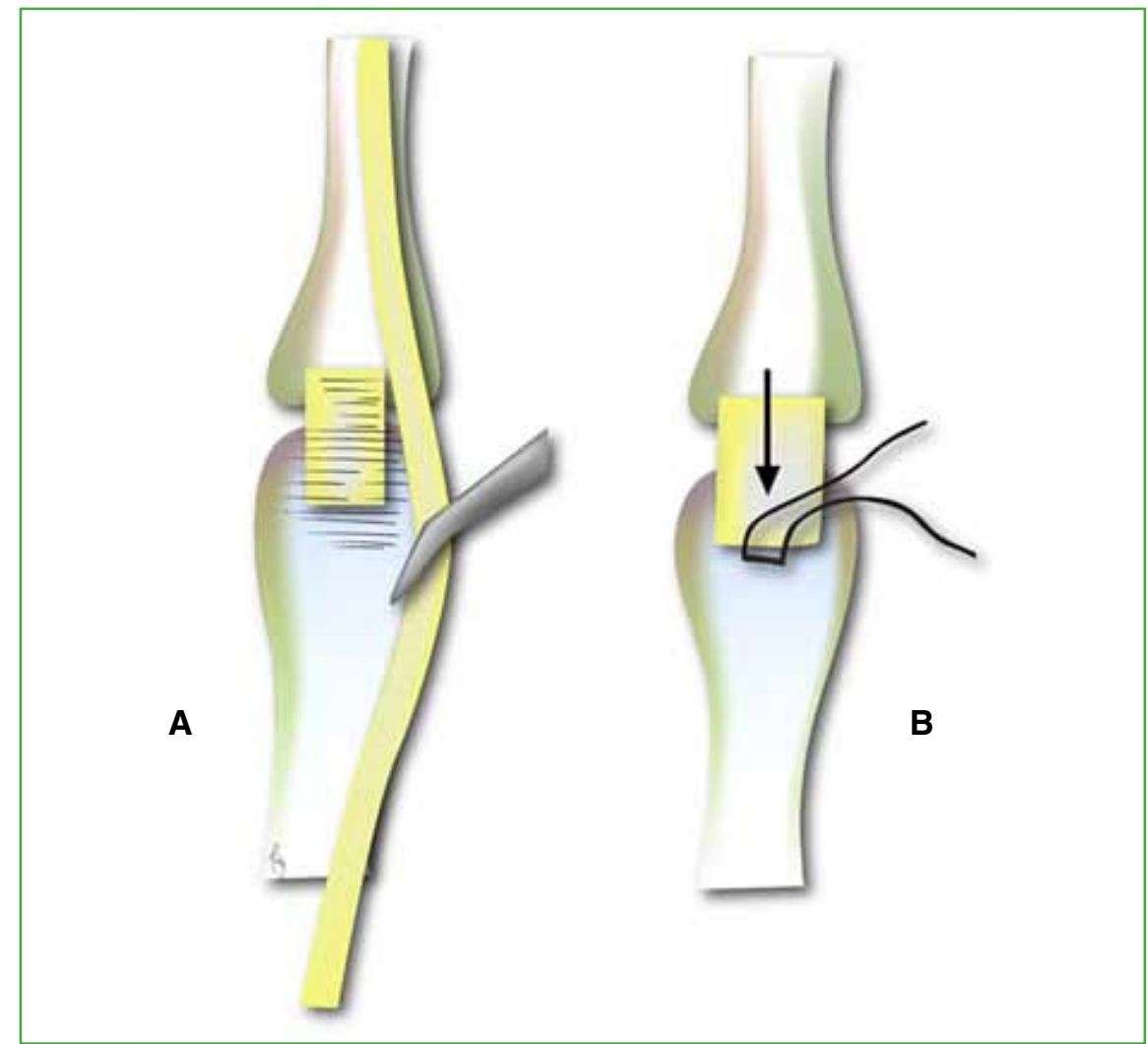

Figuras 2. A. Identificación de la cápsula volar metacarpofalángica. B. Tallado del colgajo capsular de base distal.

Conflicto de intereses: Los autores no declaran conflictos de intereses.

\section{BIBLIOGRAFÍA}

1. Bunnell S. Surgery of the intrinsic muscles of the hand other than those producing opposition of the thumb. $J$ Bone Joint Surg 1942;24:1-31.

2. Kaplan EB. Functional and surgical anatomy of the hand. Philadelphia: J.B. Lippincott Co.; 1953.

3. Zancolli EA. Claw-hand caused by paralysis of the intrinsic muscles: a simple surgical procedure for its correction. J Bone Joint Surg Am 1957;39(5):1076-80. PMID: 13475406

4. Mikhail IK. Bone block operation for claw-hand. Surg Gynecol Obstet 1964;118:1077-9. PMID: 14143460

5. Bunnell S. Surgery of the hand. Philadelphia: J.B. Lippincott Company; 1944.

6. Riordan DC. Tendon transplantations in median-nerve and ulnar-nerve paralysis. J Bone Joint Surg Am 1953;35(2):312-20. PMID: 13052603

7. Bouvier M. Note sur une paralysie partielle des muscles de la main. Bull Acad Nat Med (Paris) 1851-1852;18:125-39. 